\title{
An updated USACE approach to the evaluation of coastal total water levels for present and future flood risk analysis
}

\author{
Heidi Moritz ${ }^{1 \mathrm{a}}$, Kathleen White ${ }^{2}$ and Ben Gouldby ${ }^{3}$ \\ ${ }^{1}$ US Army Corps of Engineers, Portland District, Portland, Oregon, United States \\ ${ }^{2}$ US Army Corps of Engineers, Institute for Water Resources, Washington, D.C., United States \\ ${ }^{3} \mathrm{HR}$ Wallingford, Oxfordshire, United Kingdom
}

\begin{abstract}
USACE coastal missions, operations, programs, and projects must be resilient to the full range of forseeable water levels, including extreme water levels, as well as the changing conditions that those water levels can induce at a project location. Water level range, magnitude of extremes, and frequency will all contribute to the stability, operation, and performance of a given project. Understanding which component of total water level or combination of components controls performance (and at what time scale) is critical to the design and evaluation of a project. Being aware of the different cross shore zones of total water level calculation and impacts informs exposure and impact assessments. Estimating future conditions over the project life recognizes that there will be both stationary and nonstationary contributions to the total water level (TWL) over time, necessitating the consideration of scenarios in project alternative development. An adaptive management approach provides a process for dealing with future uncertainties and involves developing plans that envisage a range of futures, incorporates ongoing monitoring, and permits transitions from one approach to another. Identifying thresholds beyond which stability or performance are adversely impacted is an important way to understand current and future vulnerability with respect to water levels, especially within the flood risk mission area. The USACE total water level Engineering Technical Letter (ETL) in development will guide how to evaluate total water levels for USACE coastal missions.
\end{abstract}

\section{Introduction}

A wide range of infrastructure and population at risk exists around the coastline of the US. US Army Corps of Engineer (USACE) missions, operations, programs, and projects in the coastal zone must be resilient to the full range of water levels, including extreme water levels, as well as the changing conditions that those water levels can induce at a project location. These mission areas relate to levees and coastal protection infrastructure, ports and harbour developments and navigation. There is a requirement for maintenance of existing legacy infrastructure as well as the consideration of new project builds and new developments.

Water level ranges, magnitudes, and frequencies will all contribute to the stability, operation, and performance of a given project. Breaking a total water level down into the contributing components is essential to understanding risk as well as potential changes over time. Projecting future conditions over the project life recognizes that there will be both stationary and nonstationary contributions to the total water level (TWL) over time necessitating the consideration of scenarios in project alternative development. An adaptive management approach provides a process for dealing with future uncertainties and involves developing plans that envisage a range of futures, incorporates ongoing monitoring, and permits transitions from one approach to another.

Any description of water level components is connected to a point in time described by the data and the processing assumptions. Identifying thresholds beyond which stability or performance are adversely impacted is an important way to understand current and future vulnerability with respect to water levels. Understanding which component of TWL or combination of components controls performance (and at what time scale) is critical to the design and evaluation of the project. Flood risk impacts both stability and performance of USACE projects. Fully understanding current and future changes in flood risk will impact resilience and sustainability of USACE projects.

This paper describes the development of new guidance, in the form of an Engineering Technical Letter (ETL), on how coastal water level ranges can be incoporated within flood risk analysis, for the purposes of coastal project design and hazard mapping within the US. The guidance summarises methods and data available and advises on how these can be appropriately utilised in practice.

\footnotetext{
${ }^{1 \mathrm{a}}$ Corresponding author: Heidi.p.moritz@usace.army.mil
} 
This guidance forms part of a series of guidance documents produced by the USACE that has helped to shape best practice with respect to changing sea levels in the US since 1986.

\section{Principles}

Effective coastal analysis and design requires the identification and analysis of controlling water level components which will vary with project type, design life, location of the project as well as adjacent water body characteristics. Communication of the frequency of occurrence of components, influence on other design variables, and translation to project performance over time, as well as the potential for exceedance over time will be essential to informed project alternative selection. Regardless of the mission area or project type, the principles that identify the requirements for total water level analysis at a project include the following items, divided into Total Water Level Components and Component Analysis and Use in Design and Performance Assessment.

\section{Total Water Level Components:}

1. Breaking a total water level down into the contributing components is essential to understanding risk and potential changes over time.

2. A project may have more than one controlling water level depending on the design and performance functions relevant to the project.

3. The controlling water level may be the result of combinations of either coincident events or forcing/receiving area values.

4. The controlling water level may be a value other than the extreme high or the extreme low. In addition, duration, frequency, and rate of change may be of importance to project performance and stability.

Component Analysis and Use in Design and Performance Assessment:

5. Analysis of total water levels is a separate activity from the selection of total water level values for design and project performance assessment.

6. Data availability, data quality, and processing procedures may influence the accurate and complete description of the forcing and receiving climate.

7. The variability of other design or forcing parameters that are a function of water level may control design/performance limit states.

8. Any description of water level components as well as influence on alternative performance is connected to a point in time described by the data and the processing assumptions. Variability over increasing time scales from hours to decades of the relevant parameters may influence performance and adaptability of the range of project alternatives.

\section{Existing flood hazard mapping for US}

The Federal Emergency Management Agency (FEMA) prepares Flood Insurance Studies (FISs) and Flood Insurance Rate Maps (FIRMs) which are used by FEMA to administer the National Flood Insurance Program (NFIP). FIRMs display the areal extent of the one-percent annual chance flood. These areas are termed Special Flood Hazard Areas (SFHAs). SFHAs are divided into flood hazard zones based on the type of flood hazard. Also depicted on FIRMs are Base Flood Elevations (BFEs) which represent the water surface elevations of the one-percent annual chance floods. BFEs are referenced to the North American Vertical Datum of 1988 (NAVD88), the National Geodetic Vertical Datum of 1929 (NGVD29), or a local datum where NGVD29 and NAVD88 are not available (FEMA's current policy is to ensure that all new updated maps are referenced to NAVD88 where that datum is available) [1].

In coastal areas, SFHAs, flood hazard zones, and BFEs are determined based on the Total Water Level (TWL). The models used to determine the TWL vary based on coastal geomorphology (For location-specific guidance please see the following references: [2], [3], [4].)

For example:

- For shorelines with relatively gentle slopes, the TWL is determined by adding together storm surge elevations and tidal elevations (the Still Water Level (SWL)), in addition to water elevations from wave setup and overland wave heights. The storm surge and tidal elevations may be computed from long term tide gages or numerical modeling.

- $\quad$ For shorelines with steep slopes, the TWL is determined by adding elevations from tide, wave setup, storm surge and wave runup. The storm surge and tidal elevations may be computed from long term tide gages or numerical modeling.

As part of FEMA's Risk Mapping, Assessment, and Planning (Risk MAP) effort, initiated in 2009, FEMA has been restudying and remapping coastal flood hazard data for all populated coastal areas (see Figure 1). All of these studies have been initiated and as of April 2014, approximately $10 \%$ of the coast has been completed, $47 \%$ of the coast has received preliminary flood hazard data, and the rest of the studies are in the data development phase.

All FISs and FIRMs are based on present-day hydraulic boundary conditions. Future hydraulic boundary conditions, such as projected conditions caused by rising sea levels or future development in the floodplain, are not considered when studying and mapping flood hazards for the NFIP. The issue of whether FEMA should consider future hydraulic boundary conditions in the NFIP in a regulatory manner has long been politically controversial [5] [6] and FEMA never had clear statutory authority to consider future conditions until passage of the Biggert-Waters Flood Insurance Reform Act of 2012 (BW-12). 


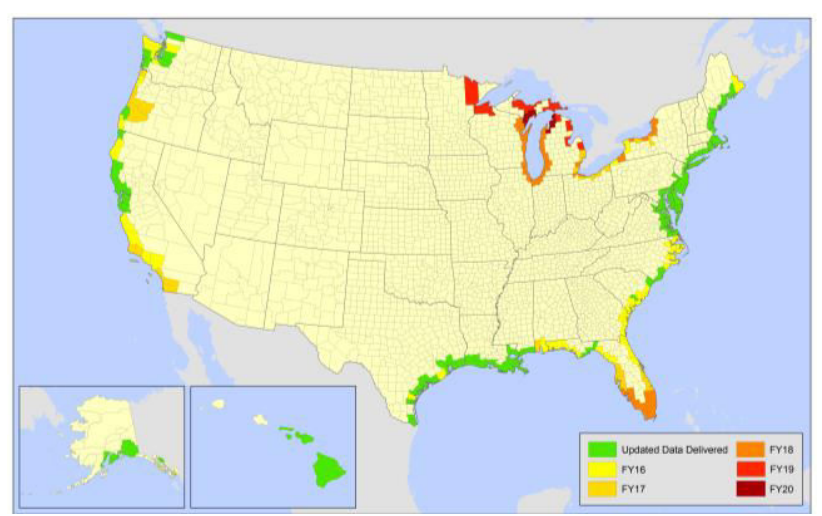

Figure 1. Schedule of coastal counties receiving updated mapping data as of January 2016

BW-12 calls for the creation of a Technical Mapping Advisory Council (TMAC) that will provide recommendations to FEMA on matters related to: (1) mapping standards and guidelines for Flood Insurance Risk Maps (FIRM), data accuracy, data quality, data currency, and data eligibility; (2) how to maintain FIRMs and flood insurance identification; and (3) procedures for delegating mapping activities to State and local mapping partners. Per the TMAC's authorizing legislation, the TMAC will also be required to recommend to FEMA methods for improving interagency and intergovernmental coordination on flood mapping and flood risk determination, and a funding strategy to leverage and coordinate budgets and expenditures across Federal agencies. Further, the TMAC will develop recommendations on how to ensure that FIRMs incorporate the best available climate science to assess flood risks, and ensure that FEMA uses the best available methodology to consider the impact of the rise in sea level and future development on flood risk.

\section{Components of total water levels}

Depending on the location of the project site, TWLs are a combination of a range of contributors and will vary in both space and time in a manner relevant to project stability and performance. The critical water level of interest will not always be the extreme high water level. At times the design water level may have more to do with duration, its combination with another design variable, or the range of water levels across the project site. Below and in figures 2 and 3 are a summary of total water level components. The contribution of each component of a TWL has the potential to significantly alter spatially and temporally varying flood hazards, resulting in a complex and non-linear problem. Figure 2 illustrates a fairly simple open coast example of TWL components while figure 3 demonstrates the potential increased complexity of TWL evaluation with complex topography and adjacent water bodies.
TWL Components:

- Mean Sea Level

- Tidal Range

- Non-tidal residual (Any elevation change in the SWL not related to the astronomical tide.)

- Seasonal cycle

- Monthly mean sea level anomalies (low frequency anomalies, El Nino, etc.)

- Storm surge (low frequency event)

- Surge amplification

- Precipitation

- River discharge

- Groundwater

- Interior ponding.

- Wave-induced components

- Wave setup and setdown

- WL change due to infragravity and wave groups

- Wave runup and swash (incident and infragravity contributions).

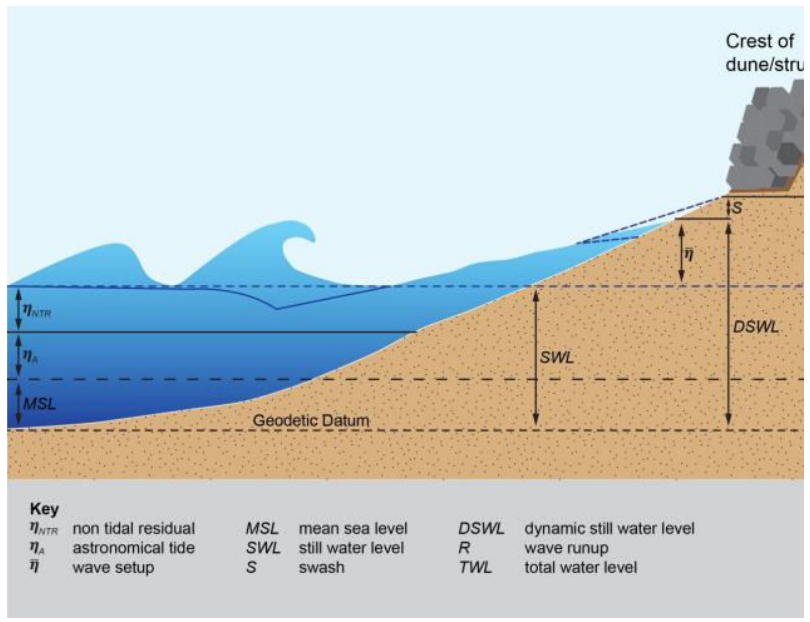

Figure 2. Generic profile view schematic of the components of total water levels (TWLs).

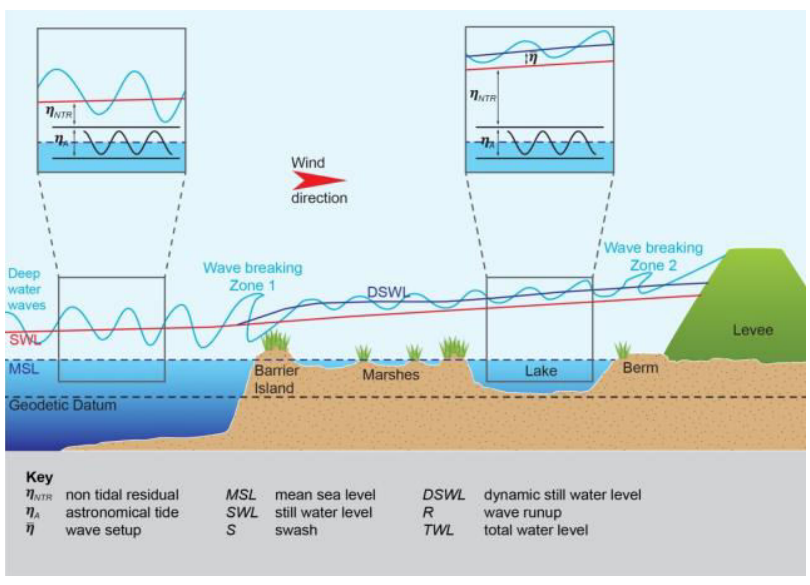

Figure 3. Profile view schematic of 'representative' U.S. Gulf Coast geometry and associated influence on total water levels. 
At any given time, the elevation of the still water level (SWL), relative to a fixed datum, is comprised of at least three components such that

$$
S W L=M S L+\eta_{A}+\eta_{N T R}
$$

where $M S L$ is the mean sea level, $\eta_{A}$ is the deterministic astronomical tide, and $\eta_{N T R}$ is the non-tidal residual. The $\eta_{N T R}$ is given as

$$
\eta_{N T R}=\text { seasonal cycle }+M M S L A+S S+Q
$$

and is defined as any elevation change in the SWL not related to the astronomical tide. The seasonal cycle can be substantial (order tens of cms) due to cyclical changes in water temperature and other forcings. The $\eta_{N T R}$ also includes low frequency monthly mean sea level anomalies (MMSLA) associated with water level variability due to water temperature and the geostrophic effects of currents (e.g., processes associated with the El Niño-Southern Oscillation, ENSO), and/or relatively high frequency components due to the presence of winds and low atmospheric pressure (e.g. storm surge, SS). In sheltered environments, precipitation, interior ponding, and river discharge, Q, also contribute significantly to $\eta_{N T R}$.

The dynamic still water level, DSWL, combines the SWL as defined above (Equations 1 and 2) with waveinduced changes to the mean sea surface and wave induced water level fluctuations on the order of minutes, and is defined as:

$$
D S W L=S W L+\bar{\eta}+\eta
$$

$\bar{\eta}$ denotes the mean water level in the presence of waves including wave setup (a super elevation of the water level due to wave breaking which reaches its maximum at the shoreline) and setdown. $\eta$ indicates additional low frequency water level fluctuations due to waves caused by processes such as bound long waves and wave groups. In many situations the DSWL should be used to compute depth limited breaking wave heights for project applications. In situations where swash processes are negligible (e.g., waves impinging directly on a breakwater), the TWL is equal to the DSWL. When waves runup on coastal protection structures or beaches, swash processes are non-negligible and

$$
T W L=D S W L+S
$$

where swash, $\mathrm{S}$, consists of contributions from both the incident band, $\mathrm{S}_{\text {inc }}$, and the infragravity band, $\mathrm{S}_{\mathrm{ig}}$, as:

$$
S=\sqrt{S_{i n c}+S_{i g}}
$$

The time varying location where the water meets the land is termed wave run-up, $R$, and includes both the wave setup and swash oscillations around the wave setup.

\section{Temporal, geomorphic, and regional variability}

USACE projects are located in widely varying regions around the continental US, influenced by significantly different water bodies as well as differences in topography. In figure 4, a representative TWL event is shown for a tide gage on each of five coastlines in the United States: Alaska, Hawaii, West Coast, Gulf Coast, and East Coast. The components of the total water level for each event are plotted in terms of absolute magnitude demonstrating the varying importance of different processes in different locations. Each event is in the top 10 most extreme water levels at its gage in terms of water level above mean higher high water. Figure 5 provides an example of variability in tidal range for the East and Gulf coasts in the US.

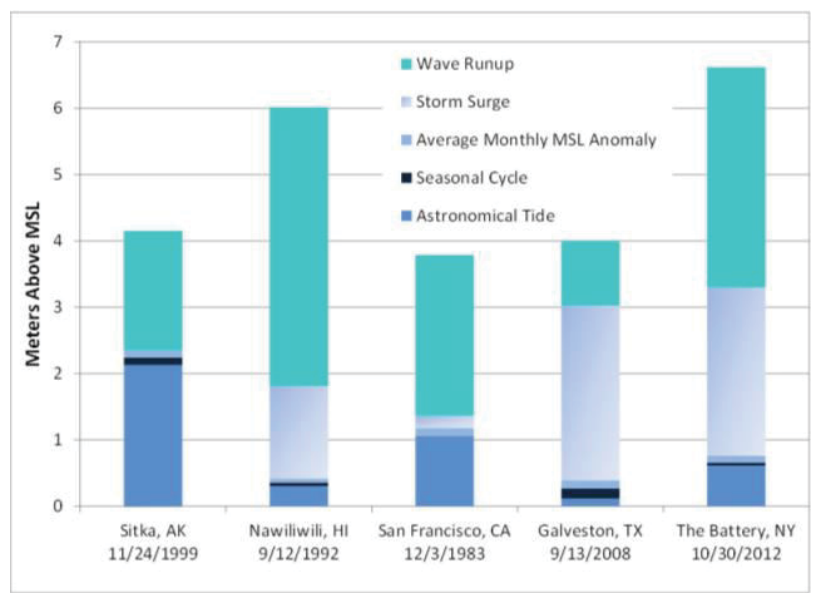

Figure 4. Total water levels for selected extreme events at 5 locations around the US shoreline.

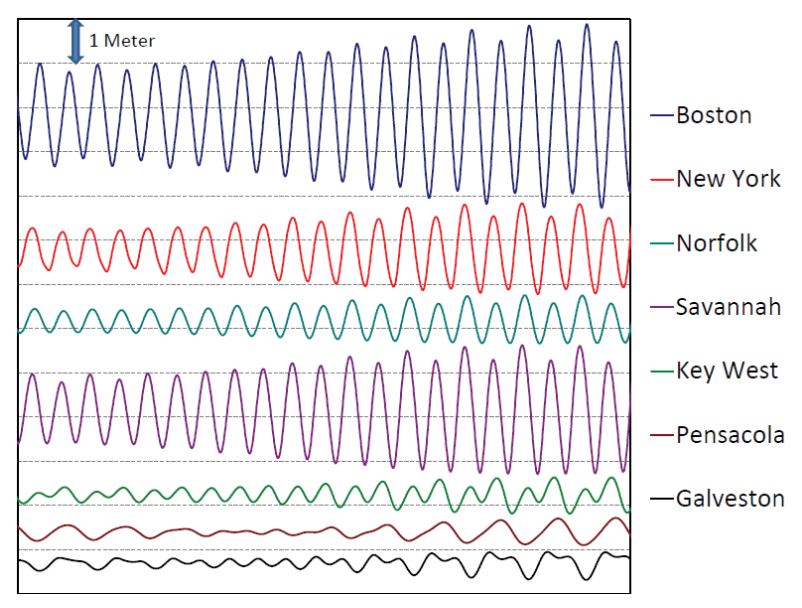

Figure 5. Characteristic tide curves near port facilities along the U.S. East and Gulf Coasts. The tides depicted are primarily semidiurnal along the East Coast. The tides at Pensacola are primarily diurnal.

The non-tidal residual $\left(\eta_{\mathrm{NTR}}\right)$ component of TWLs is often associated with noticeable impacts along the coast especially during times of higher astronomical 
tides $\left(\eta_{A}\right)$. Significant $\eta_{\text {NTRS }}$ can be produced from storm surge in response to short-period localized wind storms or in response to prolonged ocean-atmospheric forcings such as Gulf Stream transport variability along the US SE Coast or ENSO-related ocean temperature and sea surface height variability along the US West Coast. The magnitude of the $\eta_{N T R}$ depends on the types of forcing mechanisms associated with the $\eta_{\text {NTR }}$ event. Along the NE coast, strong winter storms (nor'easters) are prevalent, whereas along the SE and Gulf Coasts, winter storms are less of an impact than the rare, but extremely powerful hurricane strike. Local bathymetric characteristics also play an important controlling aspect of $\eta_{\mathrm{NTR}}$ magnitude potential. For instance, due to the narrow continental shelf along the West Coast and Pacific Islands $\eta_{\mathbb{N T R}}$ values (i.e., average to extreme) are typically much smaller than along the East or Gulf Coasts. In these areas, those TWL components connected with the tidal range and the wave components may be dominant. Duration of high energy wave events can control project design.

Figure 6a shows the 1980-2009 climatologies of daily maximum SWLs decomposed into the annual MSL, $\eta_{\mathrm{NTR}}$ and $\eta_{\mathrm{A}}$ components for regionally representative locations around the U.S. Along the NE Coast (NYC), $\eta_{\text {NTR }}$ frequency and magnitude are quite pronounced during the cool months (i.e., Oct-Apr) when nor'easters are prevalent; in the SE (Charleston) $\eta_{\mathrm{NTR}}$ magnitudes are less and more steady throughout the year. In regions impacted by the hurricanes like the SE Atlantic and Gulf Coasts, direct landfall is a major concern during the JuneNovember period and can cause large $\eta_{\mathrm{NTR}}$ storm surges, highlighted in Galveston (Figure 6a). Along the West Coast (San Francisco), $\eta_{\text {NTR }}$ are higher during winter storms but have relatively small magnitudes from bathymetric constraints. The annual MSL cycle, which forms in response to seasonal heating, wind and ocean current processes, is largest in the fall where coastal boundary currents occur such as the Gulf Stream and Loop Current system. The seasonal cycle is typically resolved by the $\mathrm{Sa}$ and Ssa tidal constituents, but transport variability can cause large anomalies [7].

Figure $6 b$ shows the relative contribution of $\eta_{\mathbb{N T R}}$ to high SWL events at 45 long-term tide gauges around the U.S. as shown in [8]. A low ratio of the average $\eta_{N T R}$ to maximum water level observations helps identify regions where the tide range is a much larger contributor than the $\eta_{\text {NTR }}$ magnitude. These regions include the West Coast (and Honolulu) where the NTR component is small (narrow continental shelf), as well as sections of the SE and NE Atlantic Coast, where the tide range is much larger than the relatively large $\eta_{\text {NTR }}$ component.
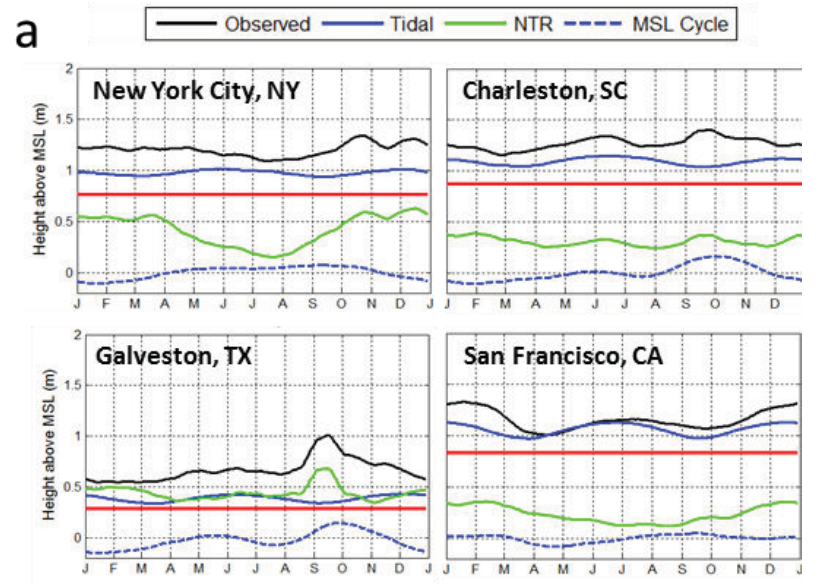

b

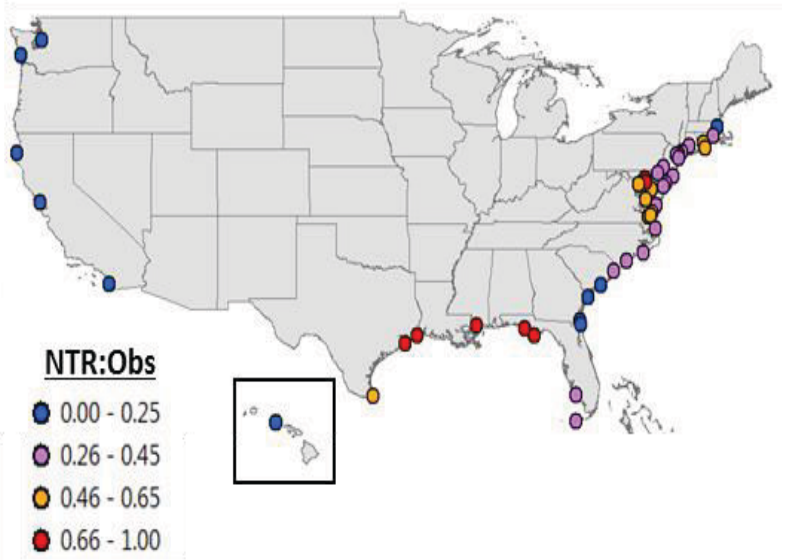

Figure 6. In a) are maximum water levels (black) per calendar day over the 1980-2009 period decomposed into a lowfrequency MSL cycle (blue dashed), predicted tide (blue; no Sa and Ssa harmonic fits) and non-tidal residual ( $\mathbf{\eta}_{\mathbf{N T R}}$; green). All series are smoothed by a 30-day running filter and plotted relative to each gauge's 1983-2001 MSL tidal datum shown with the MHHW tidal datum (red). In b) is the ratio of the average $\eta_{\text {NTR }}$ to maximum still water level observations (TWL-R) shown in (a). From [8].

\section{Project specific analysis and assessment of total water levels}

In our initial assessment of total water levels, we should consider how we measure and calculate total water level components in the project area and what assumptions we may be making.

- What sources are we using? (observations, modeling, etc.) and are all potential components captured?

- If observations are being used, does the data processing capture all components?

- What assumptions are we making about concurrence, combinations or nonlinearity?

- What TWL values do we typically report on?

- How do we describe confidence intervals and extremes over time? 
- Are non-tidal residuals related to different storm populations (tropical and extra tropical)?

In figure 7 below, different zones of total water level calculation and impact are identified beginning with deepwater conditions. As the processes analyzed get closer to the shore, interaction of the water level and wave height components may change both in combination as well as in how they are influenced by the surrounding morphology. The final backshore area is often described as the impact area for Flood Risk Reduction studies or Coastal Risk Reduction studies, however, this area also will have contributing water level components or limits which must be considered.

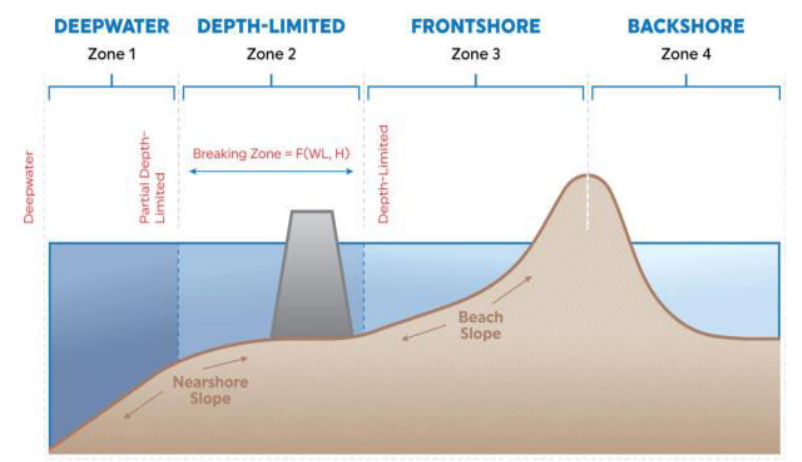

Figure 7. Zones of water level component analysis relevant to project location and dominant water level component factors.

Each mission area and project type will respond differently to total water levels depending on the project design and function. Table 1 summarizes the processes of interest as well as the possible frequencies of interest. Projects and systems of projects can be assessed in terms of both their stability against the design loading and their ability to perform their function under these loadings.

\begin{tabular}{|c|c|c|c|c|}
\hline $\begin{array}{c}\text { Performance } \\
\text { Category }\end{array}$ & Process of Interest & $\begin{array}{c}\text { Frequency of } \\
\text { Interest }\end{array}$ & Zones & $\begin{array}{c}\text { Return Period } \\
\text { Range of } \\
\text { Interest }\end{array}$ \\
\hline \multirow[t]{2}{*}{ Inundation } & short-term flooding & high frequency & 3,4 & 5 to $20 \mathrm{yrs}$ \\
\hline & long-term flooding & low frequency & 3,4 & 20 to $500 \mathrm{yrs}$ \\
\hline \multirow[t]{2}{*}{ Erosion } & short-term erosion & high frequency & 3,4 & 5 to $20 \mathrm{yrs}$ \\
\hline & long-term erosion & $\begin{array}{l}\text { low and high } \\
\text { frequency }\end{array}$ & 3,4 & 10 to $50 \mathrm{yrs}$ \\
\hline Wave Damage & $\begin{array}{c}\text { structure damage / } \\
\text { stability }\end{array}$ & low frequency & $1,2,3$ & 50 to $100 \mathrm{yrs}$ \\
\hline $\begin{array}{l}\text { Hydrostatic } \\
\text { Loading }\end{array}$ & differential loading & $\begin{array}{l}\text { low and high } \\
\text { frequency }\end{array}$ & $2,3,4$ & 50 to $100 \mathrm{yrs}$ \\
\hline $\begin{array}{l}\text { Hydrodynamic } \\
\text { Efficiency }\end{array}$ & system drainage & $\begin{array}{l}\text { low and high } \\
\text { frequency }\end{array}$ & 3,4 & 5 to 50 yrs \\
\hline $\begin{array}{l}\text { Operating } \\
\text { Conditions }\end{array}$ & $\begin{array}{c}\text { wave run-up, } \\
\text { overtopping, } \\
\text { transmission, } \\
\text { resonance }\end{array}$ & high frequency & 3,4 & 2 to $20 \mathrm{yrs}$ \\
\hline Water Quality & water quality & high frequency & 3,4 & 2 to $20 \mathrm{yrs}$ \\
\hline
\end{tabular}

Table 1. Project type water level frequency of interest (high, low, mixed)
Stability and performance may have different sensitivities to TWL. Other design variables may be influenced by TWL at the project site. Both extremes of low and high water levels should be considered. In many cases, changes in extreme highs for the project area may represent the controlling loading case, but the shift in extreme low water levels can also be important for some projects. For flood risk management, the intent is to reduce the frequency of damaging levels of flood inundation. Under the performance categories noted in table 1 , the potential loading and performance functions are summarized in table 2 below :

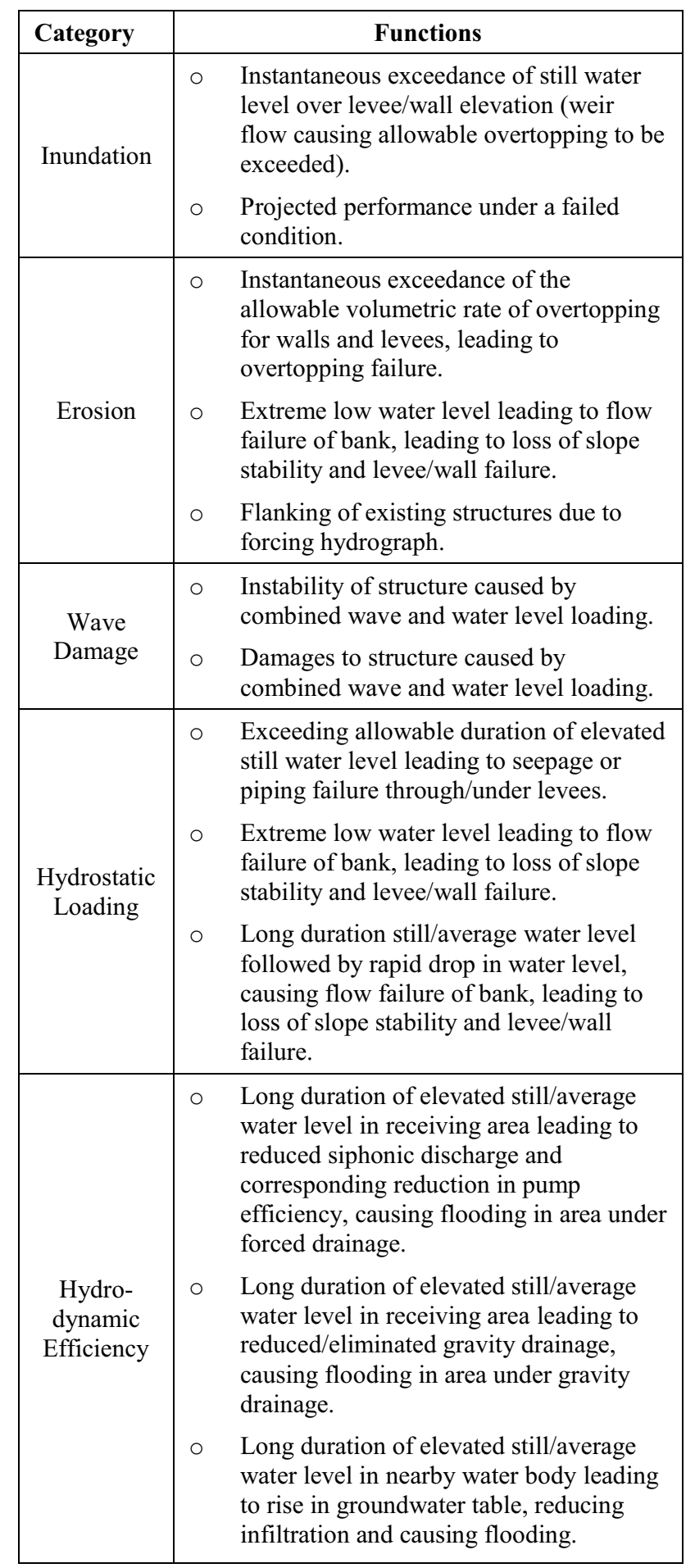

Table 2. Performance function examples 
Historical analyses of total water levels have typically focused on one of three methods: (1) extrapolation of observed data (not necessarily at project site), (2) numerical modeling, or (3) summation of limited components analyzed separately. Sometimes, these analyses lacked all total water level components, or, higher frequencies of occurrence may have been neglected. In addition, important combinations may not have been captured.

The updated USACE approach strives to improve transparency and understanding of actual total water level components over different spatial and temporal scales. The TWL is broken down into components and frequencies of interest. The TWL analysis for a given project includes the following:

1) Identify the frequency and types of water levels that influence design and performance over the project life. These water levels are broken down into relevant components as well as zones of cross shore application.

2) Provide a description of the data being used and how it is analyzed to represent components of TWL at a site. Potential gaps in the data should be identified. (period of record, location, missing components, missing combinations)

3) Describe how the methods capture all important components and determine steps to address omissions. (e.g., modeling or TWL extrapolation may not capture surge amplification or infragravity).

4) Combine the components to develop a TWL. Some components may be correlated; those can be added without affecting the overall AEP for the TWL. But some components may be independent, in which case the individual AEPs need to be combined appropriately to obtain the overall AEP for the TWL.

5) Acknowledge potential increases, non-linearity, and non-stationarity into the future of the project, specifically with respect to potential thresholds and shifts in datums.

6) Compute and report on the potential uncertainty in the methods especially with respect to future projections.

\section{Projecting future conditions}

As stated in the principles in section 2, any description of water level components is connected to a point in time described by the data and the processing assumptions. Variability over increasing time scales from hours to decades of the relevant parameters may influence performance and adaptability of the project alternatives.

It is important to take into account future changes in the different components comprising TWLs during the design process in order to guarantee high safety standards throughout the expected lifetime of a project (often 50 to 100 years or more). In most regions of the world, including the US coastline, relative sea level rise will likely be the main driver for multi-decadal changes in future TWL statistics [9]. This is generally accounted for by adding a certain amount of RSLR (as it is expected for a given target year matching the expected lifetime of the project) to the relevant return water level, i.e. the distribution function that was used for the EVA is shifted upwards according to the RSLR scenario [10]. The latter is often a political decision, which can be supported by the probabilistic assessment of RSLR scenarios [11]. Furthermore, Hunter [12] developed a technique for combining the uncertainties in existing storm tides with the uncertainties in the projections of sea-level rise. The results are given in the form of exceedance probability curves as a function of SWL. Each curve represents the likelihood of one or more flooding events at a given height and at one location, over a specified period during the $21^{\text {st }}$ century, under conditions of a prescribed emission scenario. The present storm-tide data may be derived from tide-gage observations or from a numerical model. Hunter [13] described a simple extension of this technique which enables the objective choice of a vertical allowance for sea-level rise (i.e. the amount by which coastal assets need to be raised), given the statistics of present storm tides and projections of sea-level rise. The method preserves the expected frequency of flooding events if this allowance is applied as sea-level rises.

Variations in sea level trends primarily reflect differences in rates and sources of vertical land motion. In Figure 8 areas experiencing changes in mean sea level similar to the global average rise are illustrated in green, and are not experiencing significant vertical land motion. Stations illustrating stronger positive sea level trends (yellow-to-red) are experiencing both global sea level rise and lowering or sinking of the local land, causing an apparently exaggerated rate of relative sea level rise. Stations illustrated with negative trends (blue-to-brown) are experiencing global sea level rise and a greater vertical rise in the local land, causing an apparent decrease in relative sea level. These rates of relative sea level rise reflect actual observations and must be accounted for in any coastal planning or engineering applications.

Changes in the forcing conditions, increasing storminess, for example and associated increases in TWL's are however, not as well established. Hence sensitivity analysis and/or pre-cautionary allowances are often required when considering future changes in the hydraulic conditions.

In addition to variations from location-to-location, there are also regional differences. For example, a broad region of the mid-Atlantic coastline along the United States is sinking slowly due to the glacial rebound effect of the uplift of the Hudson Bay region since the end of the last ice age. The Mississippi delta region of Louisiana is rapidly sinking due to the loading of the lithosphere and compaction of the sediments deposited by the Mississippi River. The Texas coastline is also sinking, likely due to similar causes, in addition to oil and gas extraction. The volcanically active Island of Hawaii is sinking relative to the other islands in the Hawaiian chain. Some areas of the northern California, Oregon, and Washington coastline are rising slowly due to the tectonic effects of subduction beneath the North American 
continent. Rapid uplift in southeastern Alaska is believed to be due to the melting of mountain glaciers. [14].

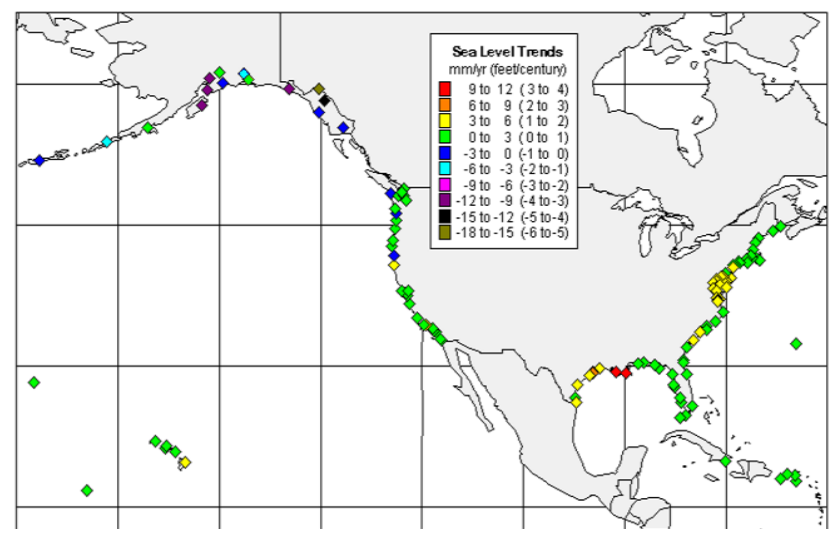

Figure 8. National map of regional mean sea level trends provides an overview of variations in the rates of relative local mean sea level observed at long-term tide stations (based on a minimum of 30 years of data in order to account for long-term sea level variations and reduce errors in computing sea level trends based on monthly mean sea level). From NOAA COOPS http://tidesandcurrents.noaa.gov/sltrends/slrmap.html [14]

Quantitative analyses for future coastal flooding events can be conducted at different levels of detail. The simplest and most direct approach would be to apply past storm tides on top of projected future sea levels [15] When contrasted to an existing project area threshold, this type of analysis can illustrate potential changes in frequency of flooding. Any future changes in the applicable cross shore zones such as cross shore and alongshore exposure and evolution constraints should be assessed. TWL-affected project processes will need to be examined individually for future changes due to TWL change. Most significant would be modifications to depth-limited wave heights, surge amplification, as well as overtopping rates. For larger levels of investment, detailed analyses on future non-linear changes to the design and performance modes will be important to future performance assessment.

Figure 9 provides an illustration of how a change in sea level in a project area can have a secondary effect on other design variables or areas of impact. This figure illustrates the movement upstream of the cross-over point between coastal-dominant and riverine-dominant processses. The importance of tracking how this may change over time at a particular project site will depend on the expected life span of the project as well as the consequences of project failure.

\section{Conclusions}

There is a wide range of infrastructure and population at risk around the coastline of the US. US Army Corps of Engineer (USACE) missions, operations, programs, and projects in the coastal zone must be resilient to the full range of water levels, including extreme water levels. Changing hydraulic boundary conditions as a result of climate change and natural land level changes is complex. Planning effective adaption of

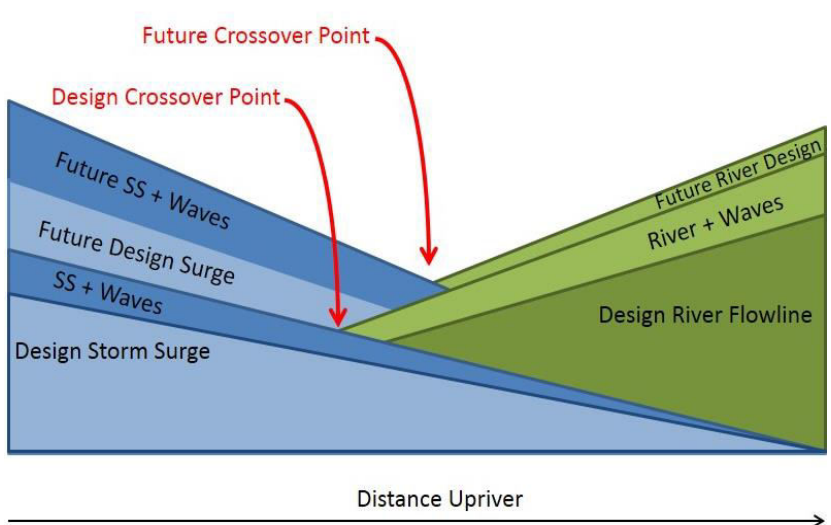

Figure 9. Illustration of upstream movement of storm surge / riverine cross-over point with future conditions

existing legacy infrastructure and designing new schemes requires comprehensive guidance. Depending on the location of the project site, TWLs may be a combination of a range of contributors and will vary in both space and time in a manner relevant to project stability and performance. Being able to break the expected range of TWLs down into components helps the practitioner understand uncertainty bands as well as potential nonstationary aspects into the future. The critical water level of interest will not always be the extreme high water level. At times the design water level may have more to do with duration, its combination with another design variable, or the range of water levels across the project site.

The updated TWL approach requires clarity and detail in identifying all contributing TWL components along with the specification of dominant components and important component combinations. A detailed summary of data sources along with any potential component or coverage gaps will highlight contributions to uncertainty in the analysis. Description of design and performance categories will lead to the identification of frequencies of interest and relevant time scales along with important design thresholds. Provision of the details of characteristics of controlling water levels and potential interactions with adjacent water bodies will inform the decision-makers on effective project alternative selection.

The USACE total water level Engineering Technical Letter (ETL) has reviewed a wide range of available information relating to TWL's around the US, including practices adopted in different countries around the world. It provides a comprehensive view on all components of TWL's and provides practical guidance on how to evaluate and explain TWL influence at a project site over the project life. In addition, guidance on appropriate methods for analysing different TWL's is also provided.

The new ETL described here represents the latest in a series of policy and technical guidance documents that have been produced by USACE to guide best practices in coastal areas subject to changing sea levels since 1986 . 


\section{Acknowledgements}

The authors would like to acknowledge the contributions to this paper of the total water level technical letter development team and specifically, Mr. Mark Crowell, physical scientist (FEMA), and Ms. Tucker Mahoney, engineer (FEMA), for their contributions summarizing the Federal Emergency Management Agency's existing and evolving guidance.

\section{References}

[1] Crowell, M.; Westcott, J.; Phelps, S.; Mahoney, T.; Coulton, K.; and Bellomo, D. 2013. Estimating the United States population at risk from coastal floodrelated hazards, in Coastal Hazards, ed. Charles W. Finkl. Springer, pp 151-183.

[2] FEMA (2005) Final Draft Guidelines for Coastal Flood Hazard Analysis and Mapping for the Pacific Coast of the United States. Available at:

http://www.fema.gov/media-library-data/20130726-154120490-9741/cg_pacific.pdf.

[3] FEMA, 2007. Atlantic Ocean and Gulf of Mexico coastal guidelines update. Available at: http://www.fema.gov/library/viewRecord.do?id=2458.

[4] FEMA, 2014, FEMA Great Lakes Coastal Guidelines, Appendix D.3 Update. Available at: http://www.fema.gov/media-librarydata/1393517296399-

fe47a15f0d1e4cab15e9c1cfce6c4619/Great+Lakes+Coast al+Guidelines_Update_Jan2014.pdf.

[5] Buckley, M.K. 1999. Forward, In: Coastal Erosion Mapping and Management (Journal of Coastal Research, Special Issue 28), eds. M. Crowell and S. Leatherman. p. 1. Royal Palm Beach, FL: Coastal Education and Research Foundation.

[6] Crowell, M., Leikin, H., and Buckley, M.K. 1999. Evaluation of coastal erosion hazards study: an overview. In: Coastal Erosion Mapping and Management (Journal of Coastal Research, Special Issue 28), eds. M. Crowell and S. Leatherman. pp. 2-9. Royal Palm Beach, FL: Coastal Education and Research Foundation.

[7] Sweet, W., Zervas C, and S. Gill (2009), Elevated east coast sea level anomaly: June-July 2009, NOAA Tech. Rep. No. NOS CO-OPS 051,NOAA National Ocean Service, Silver Spring, MD, $40 \mathrm{pp}$

[8] Sweet, et al (2014), Sweet, W. V., and J. Park (2014), From the extreme to the mean: Acceleration and tipping points of coastal inundation from sea level rise, Earth's Future, 2, doi:10.1002/2014EF000272.

[9] Menendez M., Woodworth, P. L. (2010). Changes in extreme high water levels based on a quasi-global tide- gauge dataset.. Journal of Geophysical Research. 115, C10011.

[10] Tebaldi, C., Strauss, B.H. and C.E. Zervas (2012) Modelling sea level rise impacts on storm surges along US coasts. Environmental Research Letters, 7, 014032 doi:10.1088/1748-9326/7/1/014032.

[11] Obeysekera, J., Park, J., Irizarry-Ortiz, M., Barnes, J., and Trimble, P. (2013). "Probabilistic Projection of Mean Sea Level and Coastal Extremes." J. Waterway, Port, Coastal, Ocean Eng., 10.1061/(ASCE)WW.19435460.0000154, 135-141.

[12] Hunter, (2010). "Estimating Sea-Level Extremes Under Conditions of Uncertain Sea-Level Rise", Climate Change, DOI 10.1007/s10584-009-9671-6.

[13] Hunter, (2011). “A Simple Technique for Estimating an Allowance for Uncertain Sea-level Rise", Climate Change at press (doi:10.1007/s10584-011-0332-1)

[14] NOAA CO-OPS

http://tidesandcurrents.noaa.gov/sltrends/slrmap.html

[15] Kriebel,and Geiman (2012). "The Need for a Tidal Flood Stage to Define Existing and Future Sea Level Hazards", Journal of Coastal Research, 30(5):1017-1024. 